\title{
A cross-sectional study on knowledge, attitude and practices of medical doctors towards antibiotic prescribing patterns and resistance in Khyber Pakhtun Khawah, Pakistan
}

\author{
Maira Faizullah ${ }^{1}$, Nisar-ur-Rahman ${ }^{1}$, Muhammad Ihtesham Umar ${ }^{1}$, Mudassir Anwar $^{2 *}$, Muhammad Sarfraz $^{2}$ \\ ${ }^{1}$ Department of Pharmaceutical Sciences, COMSATS Institute of Information Technology, Abbottabad, Pakistan. \\ ${ }^{2}$ College of Pharmacy, Al Ain University of Science and Technology, Al Ain, United Arab Emirates.
}

\section{ARTICLE INFO \\ Article history: \\ Received on: 12/07/2017 \\ Accepted on: 08/11/2017 \\ Available online: 30/12/2017}

Key words:

Antibiotic resistance;

Rational antibiotic use;

Physicians' knowledge;

Pakistan.

\begin{abstract}
Irrational prescribing and resistance to antibiotics are major health concerns globally. The aim of this study was to assess the physicians' knowledge, attitude and practice about antibiotic prescribing and resistance in Khyber Pakhtun Khawah (KPK), Pakistan. A cross-sectional, descriptive study was conducted using a pre-validated self-administered questionnaire. Statistical Package for Social Sciences (SPSS ${ }^{\circledR}$ ) version 23 was employed to analyze the data. A total of 320 medical practitioners participated with a response rate of $61.5 \%$. Participants generally had a good knowledge about antibiotic use. However, some flaws were observed in their practice. The Internet $(96 \%)$, antibiotic guidelines $(92 \%)$ and medical representatives $(85.9 \%)$ were reported to be the most useful sources of information. More than $70 \%$ of the respondents cited patient demand as one of the major reasons for antibiotic overuse. Antibiotic resistance was reported to be due to the failure to complete the antibiotic course by $94.1 \%$ of the respondents. The majority of the participants never had a training on the rational use of antibiotics and were in a favour of attending such training if offered. The study concluded that there is a dynamic need of training initiatives for improving antibiotics prescribing behaviour of general practitioners through the development of local guidelines and continuous education of general practitioners to promote rational antibiotic prescribing.
\end{abstract}

\section{INTRODUCTION}

Irrational use of antibiotics is a global phenomenon. More than $50 \%$ of all antibiotics are prescribed, sold or dispensed inappropriately, while $50 \%$ of the patients are not taking antibiotics correctly (WHO, 2004). Some of the factors affecting this irrational use include socio-economic status, physicians' knowledge and training, patient load, diagnostic ambiguity, availability of treatment guidelines and pharmaceutical marketing (Barden et al., 1998; Andrajati et al., 2017). The potential dangers associated with inappropriate use of antibiotics

\footnotetext{
* Corresponding Author

Mudassir Anwar, College of Pharmacy, Al Ain University of Science and Technology, P.O. Box 64141, Al Ain, United Arab Emirates (U.A.E).

Email: mudassiranwar @yahoo.com
}

are the dissemination of resistant micro-organisms, and significant adverse effects such as, increase in the duration of hospitalization, increase in the hazard of drug toxicity, and a significant increment in the cost (Buke et al., 2005). Community-acquired antibiotic resistance is on the rise because of the general suboptimal use of antimicrobials in the casualty settings (Byarugaba, 2004). In developing countries, one of the most important factors affecting antimicrobial resistance is the lack of proper training of healthcare providers regarding proper antimicrobial use and infectious disease clinical diagnosis (WHO, 2001). Other reasons include the incomplete course of treatment and self-medication (AmabileCuevas, 2010a; Rafeeque, 2016). Medical practitioners play an important role in consumption and control of antibiotics. This requires informing practitioners about how to avoid antibiotic resistance and encourage them to take steps to ensure patient wellbeing (Giblin et al., 2004). 
Literature from various countries has shown that over the years, excessive antibiotic prescribing resulted in antibiotic resistance which requires improvement, yet the ideal methods to deal with this problem remain vague (Amabile-Cuevas, 2010a; WHO 2012; Thriemer et al., 2013; Sebsibie and Gultie, 2014; Ahmad et al., 2015). Such type of improvement always requires vital changes in medical doctor's behaviour through their awareness and perceptions regarding antibiotic resistance (Wester et al., 2002; Giblin et al., 2004; Srinivasan et al., 2004). Medical doctors may modify their practice only when their attitudes, skills, beliefs and knowledge are integrated with each other potentially resulting in a decrease in antibiotic resistance (Wester et al., 2002; Giblin et al., 2004). The first step to achieve this is administering KAP surveys which are used to evaluate knowledge (K), attitudes (A) and practices (P) of medical practitioners (Thriemer et al., 2013). The bacterial resistance to available antibiotics is a serious problem in Pakistan. A sensitivity analysis may help in preventing unnecessary antibiotic prescription thereby decreasing the chances of resistance (CDC, 2014). However, the majority of antibiotics are being prescribed without culture sensitivity testing in Pakistan as reported in a study conducted in Southern Punjab region of Pakistan (Atif et al., 2017). Hence, there is a need to evaluate the current prescribing practices of antibiotics among the medical doctors and updating their knowledge to eradicate the side effects caused by prescribing wrong antibiotics against specific microbial infections. The purpose of this study is to assess the physicians' knowledge, attitude and practice about patterns of antibiotic prescribing and its resistance in Khyber Pakhtun Khawah (KPK), one of the four administrative provinces of Pakistan, in order to improve the clinical practice for the most common infections.

\section{MATERIALS AND METHODS}

\section{Study Design and Setting}

The study used a quantitative descriptive approach with a purposeful sampling of medical doctors with diverse degree of work record. Medical practitioners' knowledge, attitude and practice of antibiotic prescribing and its resistance was assessed. Data was collected from different administrative divisions of Khyber Pakhtun Khawah (KPK) namely Peshawar, Hazara, Mardan, DeraIsmail Khan (D. I. Khan), Bannu, Kohat and Malakand. Medical doctors were visited at health centers and hospitals.

\section{Study instrument}

A pre-validated 35-item questionnaire was used as the instrument. Influences to develop the questionnaire were drawn from an earlier study (Thriemer et al., 2013). The face and content validity of the instrument was established by four experienced medical professionals. The self-administered questionnaire was piloted on 20 individuals meeting the inclusion criteria and the contents were refined based on the findings of the pilot study. The internal consistency was determined through the Chronbach's Alpha (=0.64). The final questionnaire consisted of 35 questions which were divided into four sections. Questions about demographic characteristics were asked at the beginning. Four questions in Section A addressed the work experience and prescription patterns. Next nine questions were meant to assess knowledge of the current scope of antibiotics (Section B) while twelve questions in Section $\mathrm{C}$ recorded the attitude toward antibiotic prescribing. Finally, the practice of antibiotic prescribing was assessed through ten questions in Section D.

\section{Study Sample and Data Collection}

Data were collected from September 2015 to January 2016.The sample size was calculated using Raosoft ${ }^{\circledR}$, a sample size calculator. According to Pakistan Medical and Dental Council (PMDC) statistics, total 17746 medical doctors were registered in KPK during June 2015 (PMDC, 2015). For calculation of sample size, $5 \%$ margin of error and $95 \%$ confidence interval was selected. The calculated sample size was 267 . Both male and female medical doctors were included in the study while medical students and dental physicians were excluded. The questionnaire was individually handed over to the medical doctors in selected administrative divisions of KPK. Before completion of the questionnaire, the respondents were explained about the aim and nature of the study and verbal consent was taken. The questionnaires were immediately collected after being filled in by the respondents. No incentives were given to the respondents.

\section{Ethical Considerations}

The study was approved by the Research Ethics Committee of COMSATS Institute of Information Technology, Abbottabad, Pakistan. Prescribers were clearly informed about the study and were clearly guaranteed about the confidentiality of their answers. All the participations were voluntary.

\section{Data Analysis and Presentation}

The data were analyzed using descriptive statistics in SPSS $®$ version 23. Findings were presented as numbers and percentages in the form of tables and bar-charts.

\section{RESULTS}

\section{Demographic and Practice Characteristics}

A total of 520 physicians in KPK were approached and only320 respondents took part in the study with a response rate of $61.5 \%$. Among the participants, 83 were women and 237 were men. Most of the participants $(59.47 \%)$ were above 30 years old. Other demographic and practice characteristics are listed in Table 1 .

Table 1: Demographic characteristics and general information of prescribers in KPK $(\mathrm{N}=320)$.

\begin{tabular}{ll}
\hline Demographic variables & $\mathbf{n}(\%)$ \\
\hline Gender: & \\
$\quad$ Female & $83(25.9)$ \\
Male & $237(74.1)$ \\
Age: & \\
$\quad<30$ & $129(40.3)$ \\
$>30$ & $191(59.7)$ \\
\end{tabular}




\begin{tabular}{|c|c|}
\hline KPK Divisions: & $57(17.8)$ \\
\hline Peshawar & $104(32.5)$ \\
\hline Hazara & $35(10.9)$ \\
\hline Mardan & $52(16.3)$ \\
\hline D. I. Khan & $23(7.2)$ \\
\hline Bannu & $20(6.3)$ \\
\hline Kohat & $29(9.1)$ \\
\hline \multicolumn{2}{|l|}{ Malakand } \\
\hline $\begin{array}{l}\text { How many years have you been working after you } \\
\text { graduated from medical school? }\end{array}$ & $33(10.3)$ \\
\hline I am a trainee in medicine & $77 \quad(24.1)$ \\
\hline Less than one year & $89(27.8)$ \\
\hline $1-3$ years & 67 (20.9) \\
\hline $4-6$ years & $54 \quad(16.9)$ \\
\hline \multicolumn{2}{|l|}{7 years and more } \\
\hline To whom do you prescribe antibiotics? & $53 \quad(16.6)$ \\
\hline Patients at out-patient department & $61 \quad(19.1)$ \\
\hline Hospitalized patients & $206(64.4)$ \\
\hline \multicolumn{2}{|l|}{ Both } \\
\hline How often do you prescribe antibiotics? & $108(33.8)$ \\
\hline More than once daily & (14.7) \\
\hline Once daily & $107(33.4)$ \\
\hline $3-5$ times a week & $19 \quad(5.9)$ \\
\hline $1-2$ times a week & (12.9) \\
\hline Less than once a week & \\
\hline \multicolumn{2}{|l|}{$\begin{array}{l}\text { How confident are you about your knowledge of } \\
\text { antibiotics? }\end{array}$} \\
\hline Very confident & $199 \quad(62.2)$ \\
\hline Confident & $22 \quad(6.9)$ \\
\hline Neutral (I have no idea) & $25 \quad(7.8)$ \\
\hline A bit confident & $05 \quad(1.6)$ \\
\hline Not at all confident & \\
\hline
\end{tabular}

\section{Knowledge on Antibiotics}

Most of the respondents $(94.7 \%)$ agreed that antibiotic resistance is an important problem worldwide and especially in Pakistan. About $90 \%$ of the respondents agreed that antibiotics are overused in the community with $39.3 \%$ who strongly agreed that it is a major problem in their own daily practice. More than half $(55 \%)$ of the respondents disagreed that antibiotics can be used to treat viral infections and $42.1 \%$ of the respondent also disagreed that antibiotics will speed up the recovery of cold and similar conditions. The majority $(63.7 \%)$ agreed that antibiotics are available on medical stores like non-prescription medicines and $43.1 \%$ of the respondents agreed that efficacy will be better if the antibiotics are newer and the price is higher (Figure 1).

\section{Attitude towards Antibiotic Prescribing}

The majority (95\%) of the respondents strongly agreed that antibiotic resistance rate is important to know and $88.7 \%$ strongly agreed that cultural sensitivity test is also important before prescribing. However, this can only be done by the support of microbiology laboratory. According to our results, there was no single doctor who performed the culture sensitivity test. The findings are summarized in Figure 2. The majority of the respondents from all divisions admitted that it is important to know the resistance rate of bacteria in local settings and cultural sensitivity test is important for prescribing. Peshawar and Hazara division respondents disagreed that selection of antibiotics is influenced by the availability of antibiotics. Respondents from all divisions agreed that patients demand for antibiotics is the major reason that contributes toward the abuse of current antibiotics. Among different divisions, only the majority of Hazara division respondents disagreed that antibiotics that are available locally are of bad quality and for antibiotics selection, local guidelines are more useful than international guidelines. All respondents were interested in a training program to be initiated.

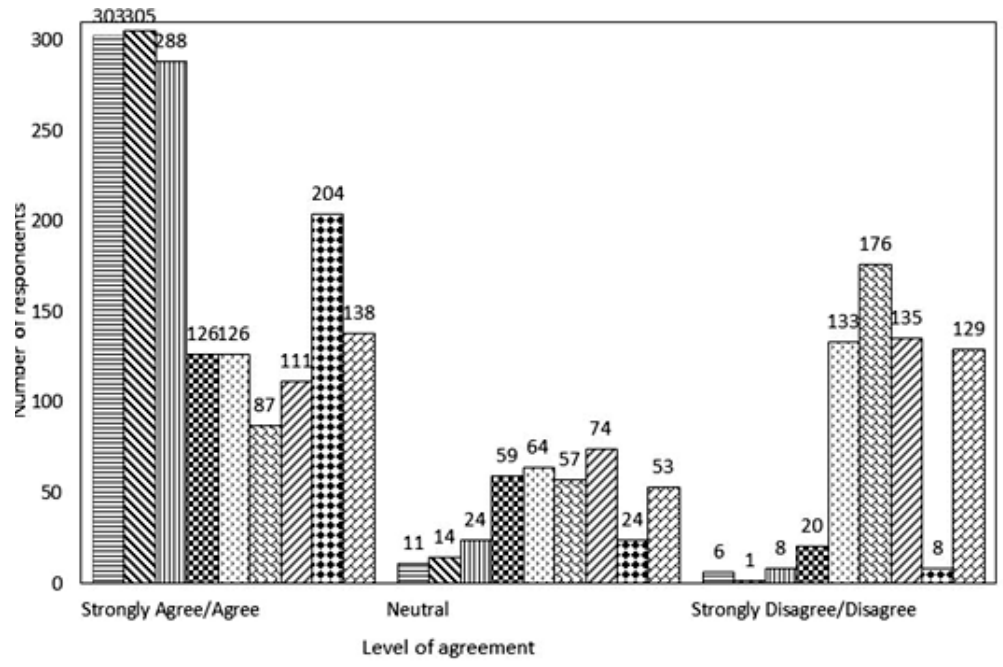

EAntimicrobial resistance is a world-wide problem

SAntimicrobial resistance is a problem in my country

口Antibiotics are over-used in the community in KPK.

Antimicrobial resistance is a problem in my daily practice

II find it hard to select the correct antibiotic

ECan antibiotic be used to cure infections caused by viruses ?

QDo you think the use of antibiotic will speed up the recovery of cold, cough and other diseases?

Is antibiotic available OTC at stores or pharmacies?

DIs the efficacy better if the antibiotic are newer and the price is higher?

Fig. 1: Knowledge of antibiotic prescribers $(\mathrm{N}=320)$. 


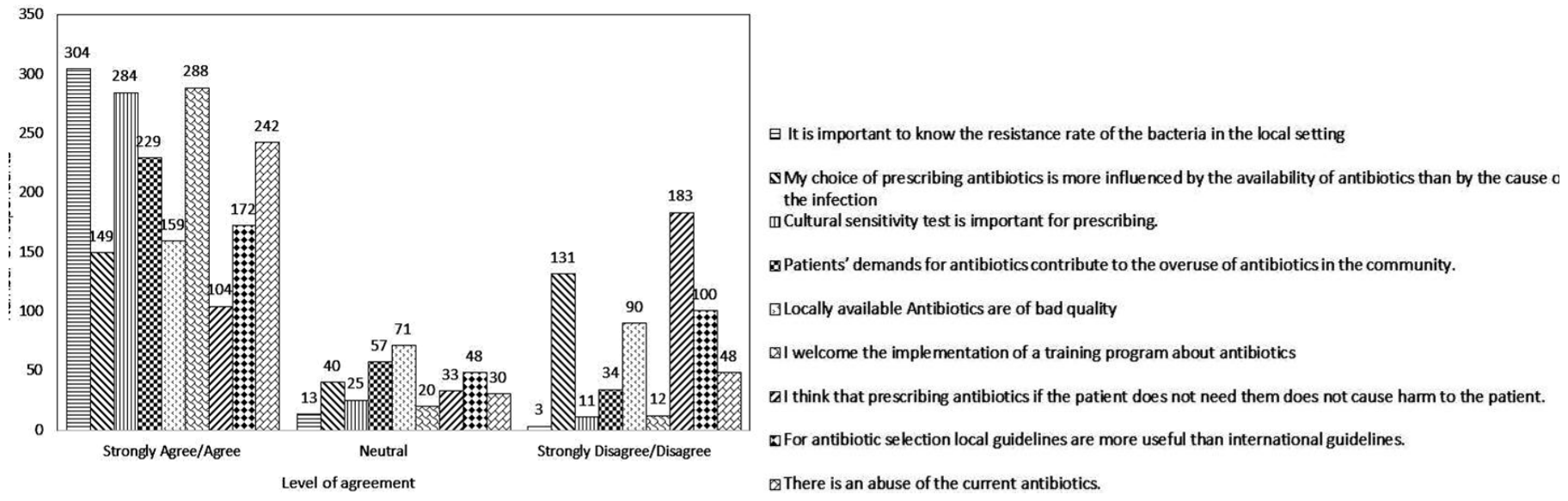

Fig. 2: Attitude of antibiotic prescribers $(\mathrm{N}=320)$.

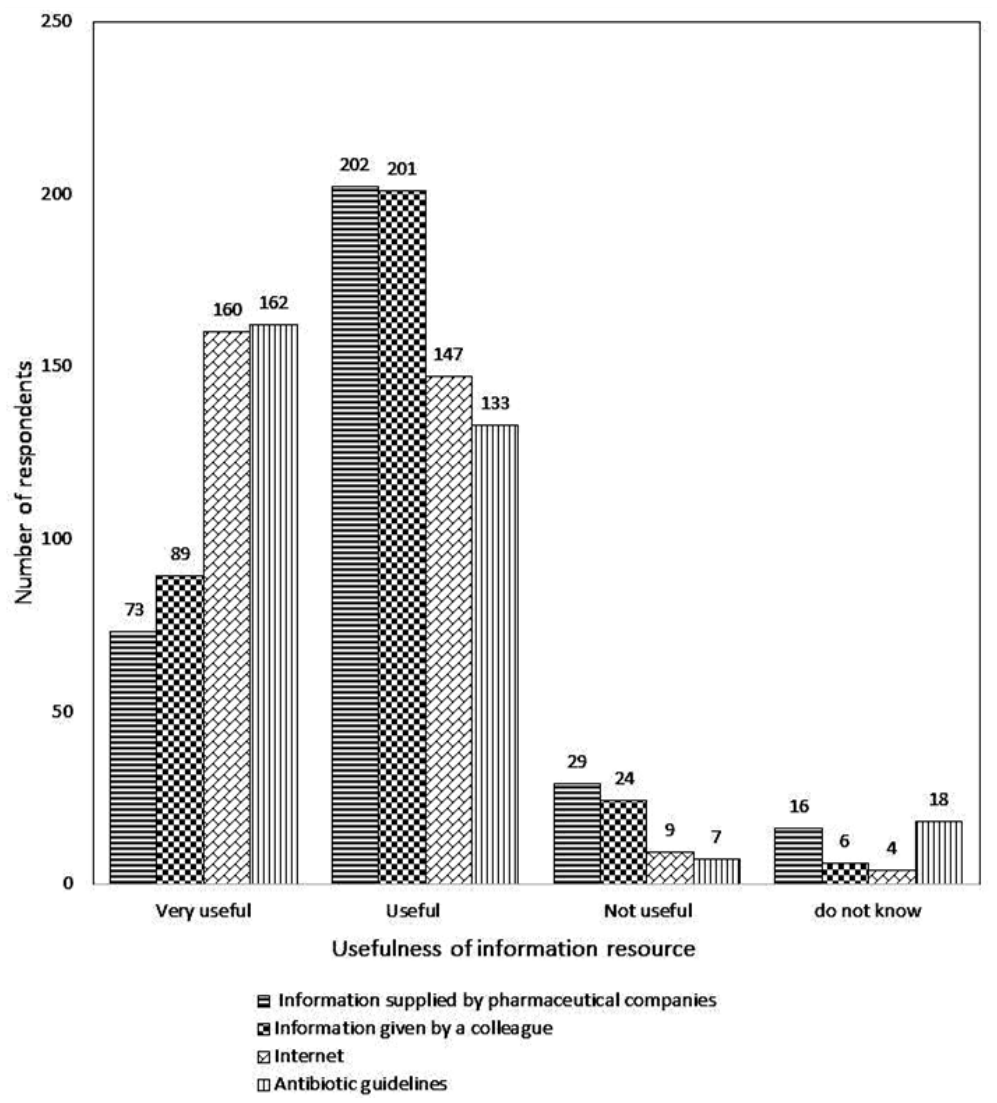

Fig. 3: Sources of Information's for antibiotic prescribing.

\section{Antibiotic Prescribing Practices}

Table 2 shows the overall response about prescribing practices in different divisions of KPK. The majority (93\%) of the respondents agreed that no antibiotic treatment is required in case of diarrhea and only $19 \%$ were of the same view for rhinitis. Less than $24 \%$ of the respondents replied correctly for parenteral administration of aminoglycosides once daily and less than $40 \%$ replied correctly that no antibiotics are used if the patient is moderately febrile. Figure 3 shows the overall response about sources of information for antibiotic prescribers with internet reported to be the most useful and accessible source (96\%) followed by antibiotic guidelines (92\%) and pharmaceutical companies $(85.9 \%)$.

About $70 \%$ of the doctors did not receive any training about antibiotics in the past. Figure 4 shows the overall response about contributing factors to antibiotic resistance in KPK. Nearly $94.1 \%$ of the respondents thought that patient does not finish his or her treatment followed by $79.7 \%$ who admitted that antibiotics are not prescribed according to the bacterium that causes the infection. 
Table 2: Antibiotic prescribing practices.

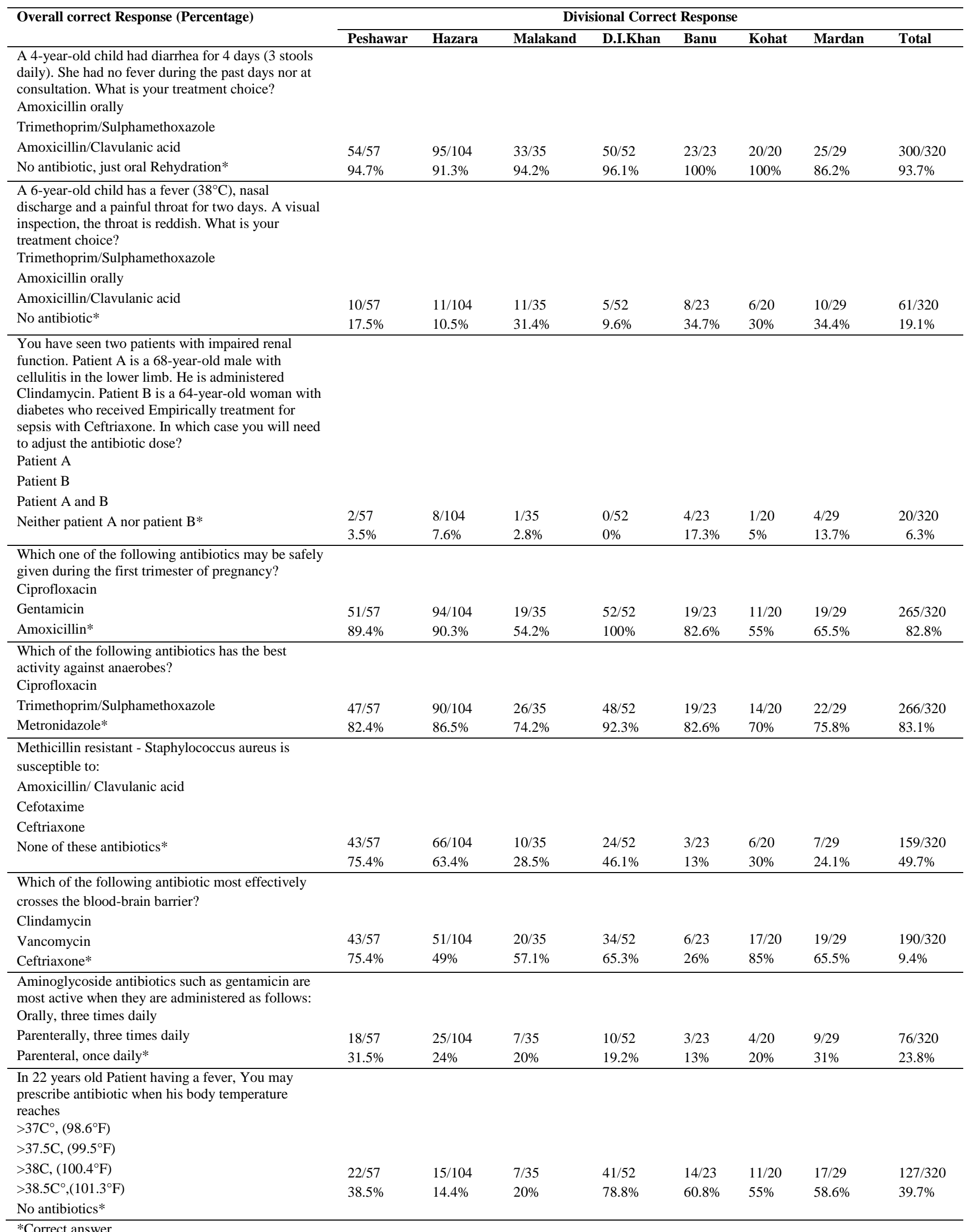

*Correct answer 


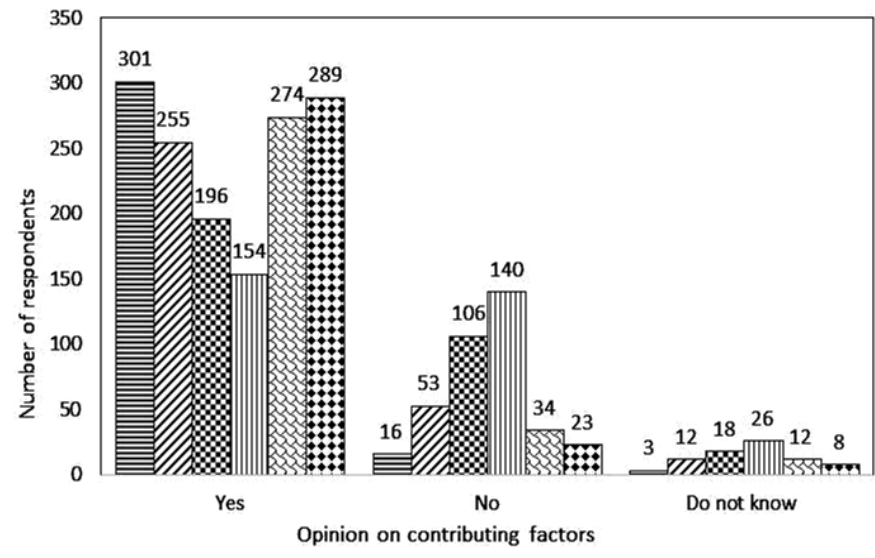

EPatient does not finish treatment

$\square$ Antibiotics are not prescribed to the bacterium that causes the infection

Antibiotics given at a low dose

mAntibiotics are of bad quality

QThere is too much prescription and too much consumption of antibiotics

gSelf-medication by the patient

Fig. 4: Contributing factors of antibiotic resistance.

\section{DISCUSSION}

This study provides a detailed information of knowledge and practices regarding antibiotic use among registered medical practitioners practicing in KPK, Pakistan. Due to male dominance (more than $65 \%$ of the registered medical practitioners were men) (PMDC, 2015), more data was obtained from male practitioners.

Antibiotics in Pakistan is reportedly sold as OTC (over the counter) medications in pharmacies. This has not been reported first time in this study but a number of previous studies have documented the same (Anwar et al., 2015; Haseeb and Bilal, 2016; Ashraf et al., 2017). A previous study in India reported that $75 \%$ of pharmacy clients take their decision of antibiotics purchasing based on the experiences of their peers with antibiotics prescribed by a senior medical doctor (Dua et al., 1994; Livorsi et al., 2015). Another issue worth mentioning is that the physicians instead of using narrow or single spectrum antibiotics prefer wide spectrum ones, even if these antibiotics have no indications (Khan et al., 2013). The government encourages the use of generic medicines for prescriptions and procurements, however; the negative perceptions among the doctors, pharmacists and even the general public about the quality and efficiency of generics as reported in a systematic review, might be the reason that discourages the practitioners from prescribing the generics (Colgan et al, 2015). Similarly, there have been concerns over the generic medication ingredients coming from possible sources with less oversight, such as India and China (Chu and Hamp, 2012). As reported in a 2005 study, $20 \%$ of generic ciprofloxacin eye drops purchased in India were of low potency, and some preparations of the antibiotic content were low enough to negatively affect the treatment outcomes (Weir et al., 2005).
In our study none of the respondents performed or advised for the culture sensitivity test which is consistent with earlier studies conducted in Pakistan whereby culture sensitivity testing was non-existent (Atif et al., 2017) and in Bangladesh reporting that $90 \%$ of the antibiotics were prescribed without laboratory findings (García et al., 2011). This practice of not conducting culture sensitivity test may exacerbate the problem of antibiotic resistance in Pakistan as the sensitivity analysis is one of the various means to minimize the occurrence of antibiotic resistance and promoting rational prescription of antibiotics (CDC, 2014). A report from Trinidad suggested that doctors did not usually demand laboratory analysis as they felt that culture sensitivity tests are useless and time-consuming (Mohan et al., 2004). Likewise, in Pakistan, the absence of laboratory services was found to be one of the major reasons of excessive antimicrobial prescribing (Nizami et al., 1996).

Demand and pressure from the patients were reported to be one of the predominant factors driving the irrational prescribing of antibiotics which is consistent with the findings from low and middle-income countries. For example, a survey of pediatricians and patients' caregivers in Venezuela discovered that approximately $87 \%$ of the physicians felt pressured by patients in prescribing antibiotics; half of the patients said that they had demanded antibiotics and one-quarter admitted that they had attained a prescription (Britten and Ukoumunne, 1997). Many studies conducted in other developing countries such as the one conducted in Tamil Nadu State of India revealed that antibiotics are often overprescribed and misused by health providers and one of the important reasons behind this was patient desires and satisfaction issues that lead to inappropriate antibiotic use (Fluit et al., 2001; Madani et al., 2001; Smith and Coast, 2002; Pedersen et al., 2007; Shahid et al., 2017)

Similarly, among the reasons causing antibiotic resistance, patient-related problems (self-medication) existed more often. A number of recent studies conducted in Pakistan have presented the similar findings and the common reasons for such practices included low socio-economic status and level of education, previous experience, and ease of purchasing antibiotics from pharmacies without prescription (Naveed et al., 2015; Hameed et al., 2016; Hanif et al., 2016). This is also consistent with a French study which stated that parents generally preferred self-medication for mild pathologies in their children (Escourrou et al., 2010). A study in China showed that children had received self-medication by $51 \%$ of the parents (Bi et al., 2000). Many studies in developing countries presented that antibiotics are used most commonly in everyday practice, whereas the most common symptom of the use of antibiotics was fever. Management of fever with antibiotics without microbiological investigations has been considered as a primary factor of irrational drug use in the developing countries (Istúriz and Carbon, 2000). Similarly, More than half of the respondents agreed that if antibiotics are administered at lower than the required doses that may cause the antibiotic resistance which is in line with the findings from Congo (Thriemer et al., 2013). Such findings suggest that sincere 
measures need to be taken to educate people on the appropriate use of antibiotics.

A large number of the respondents stated that they referred to the information provided by pharmaceutical companies. A number of earlier studies concluded that advertising activities promoted the random supply of antimicrobial agents in some cultures (Kamat et al., 1997; Prats et al., 2000; Wolffers, 1987). Numerous studies have reported that the marketing tactics of pharmaceutical industries play an important role in increasing the prescribing and sale of certain drugs (Wolffers, 1987; Haak, 1988; van Staa, 1993; Ijoma et al., 2010; Workneh et al., 2016). A regression analysis conducted on data from selected cities of Pakistan exposed that the promotional tools of pharmaceutical companies had a substantial impact on physicians' prescribing practices (Ali et al., 2015). The fair information available about antibiotics is a requirement intended for suitable antibiotic suggesting (World Health Organization, 2012). Information from pharmaceutical industries was graded highest inaccessibility. Although lower most valued for effectiveness, this approves the prominent part of pharmaceutical companies to affect the prescribing practices in developing countries (Amabile-Cuevas, 2010b).

The finding that the majority of the respondents had not received any formal training on antibiotic prescribing describes the mismatch between knowledge and practice as reported in this study. This, coupled with the willingness of the respondents to attend such training if offered suggests that as a part of Continuing Professional Development (CPD), workshops or seminars on how to prescribe antibiotics should be organized on a routine basis by the health department.

The importance of treatment guidelines cannot be denied as a good number of respondents agreed that antibiotic guidelines must be followed for antibiotic prescribing. This relates to the surveys from other countries in which the antibiotic guidelines ranked high by the participants with a demand to develop local antibiotic guidelines (García et al., 2011; Guerra et al., 2007). Similarly, when prescribing antibiotics, there was a little tendency to consult colleagues (Bennish and Khan, 2010; Srinivasan et al., 2004). Today, several countries like Netherlands and Britain are concentrating on public education so as to promote the rational use of antibiotics in the local community in order to minimize the development of resistance to antibiotics (Davey et al., 2002; Stille et al., 2008). Although it has been proposed that public education alone may not improve the tendency to abuse and misuse antibiotics in the society (McNulty et al., 2007), other researchers argue that providing perfect antibiotic guidelines to medical prescribers may deliver a more effective and quicker route to rational use of antibiotics, ultimately reversing the current trend (Amabile-Cuevas, 2010a; Metlay et al., 2002).

The study has important limitations. Firstly, the findings of this study cannot be generalized for the whole country as the study was conducted in one province. Furthermore, in recent years, KPK government has made significant improvements in the health sector which further limits the generalizability of the findings and suggests the need for conducting similar studies in other provinces. Secondly, there might be variations among the study participants in terms of their experience with antibiotics based on the type of speciality they were working in. However, the aim of the study was to draw an overall picture of practitioners experience with antibiotics and we did not categorize our participants based on the clinical speciality. Thirdly, the ingrained limitations of survey research such as recall bias, potentially dishonest answers from the respondents and systematic and random errors were unavoidable. Nevertheless, survey research is a cost-effective and efficient mean of collecting information about a population.

The study has some noteworthy implications on policy and practice. The findings indicate that there is a dire need to provide training to the prescribers and educate the masses to ensure the rational use of antibiotics. On the policy front, more stringent strategy is required to minimize the sale of antibiotics as OTC medications so as to minimize the occurrence of antimicrobial resistance. Further work to recognize and appreciate the full degree of antibiotic usage and irrational prescribing in other provinces and rural areas of the country is warranted.

\section{CONCLUSION}

The study concludes that the practitioners generally had a good level of knowledge about antibiotics. However, some shortcomings were observed in the prescribing pattern. Culture sensitivity test, though recognized by the respondents as an important strategy to minimize the chances of resistance, was not a common practice. The availability of antibiotics without prescription and failure of the patients to complete their antibiotic course were regarded as the most common contributing factors to antibiotic resistance. The practitioners generally relied on information from internet, treatment guidelines and pharmaceutical companies, however; no formal training sessions were attended by the majority of the prescribers. Therefore, the study highlights the need to regulate the prescribing of antibiotic and training initiatives for improving antibiotics prescribing behavior of medical doctors in Pakistan. Finally, local guidelines and continuous education of general health professionals would be an essential step to promote rational use of antibiotics.

\section{Financial support and sponsorship: Nil.}

Conflict of Interests: There are no conflicts of interest.

\section{REFERENCES}

Ahmad A, Khan MU, Patel I, Maharaj S, Pandey S, Dhingra S. Knowledge, attitude and practice of B.Sc. Pharmacy students about antibiotics in Trinidad and Tobago. J Res Pharm Pract, 2015;4:37-41.

Ali Z, Rana MLT, Mahmood A, Hanan MA, Noshina S, Nail K. Relationship between doctors' prescribing behavior and pharmaceutical promotional tools: A Pakistani case. Iran J Public Health, 2015; 44(5): 709-10.

Amabile-Cuevas C. Antibiotic resistance in Mexico: a brief overview of the current status and its causes. The Journal of Infection in Developing Countries, 2010a; 4(03):126-131. 
Amábile-Cuevas CF. 2010b. Global Perspectives of Antibiotic Resistance. In: Sosa A, Byarugaba D, Amábile-Cuevas C, Hsueh PR, Kariuki S, Okeke I, eds. Antimicrobial Resistance in Developing Countries. New York: Springer 3-13.

Andrajati R, Tilaqza A, Supardi S. Factors related to rational antibiotic prescriptions in community health centers in Depok City, Indonesia. J Infect Public Health, 2017; 10:41-48.

Anwar M, Green J, Norris P, Bukhari NI. Self-medication, home remedies, and spiritual healing: common responses to everyday symptoms in Pakistan. Health Psychol Behav Med, 2015; 3(1):281-295.

Ashraf F, Hafeez A, Imtiaz F, Ayub A, Imtiaz H. Antibiotic Dispensing and Prescription Pattern in Pharmacies of Islamabad and Rawalpindi: Pakistan. Int J Collab Res Intern Med Public Health, 2017; 9(5):683-692.

Atif M, Azeem M, Saqib A, Scahill S. Investigation of antimicrobial use at a tertiary care hospital in Southern Punjab, Pakistan using WHO methodology. Antimicrob Resist Infect Control, 2017; 6:41.

Barden LS, Dowell SF, Schwartz B, Lackey C. Current attitudes regarding use of antimicrobial agents: results from physicians' and parents' focus group discussions. Clin Pediatr, 1998; 37(11):665-671.

Bennish ML, Khan WA. 2010. What the future holds for resistance in developing countries. In: Sosa A, Byarugaba D, AmábileCuevas C, Hsueh PR, Kariuki S, Okeke I, eds. Antimicrobial Resistance in Developing Countries. New York: Springer 37-57.

Bi P, Tong S, Parton KA. Family self-medication and antibiotics abuse for children and juveniles in a Chinese city. Soc Sci Med, 2000;50(10):1445-50.

Britten N, Ukoumunne O. The influence of patients' hopes of receiving a prescription on doctors' perceptions and the decision to prescribe: a questionnaire survey. BMJ, 1997; 315(7121):1506-1510.

Buke C, Hosgor-Limoncu M, Ermertcan S, Ciceklioglu M, Tuncel M, Köse T, Irrational use of antibiotics among university students. J Infect, 2005; 51(2):135-139.

Byarugaba DK. A view on antimicrobial resistance in developing countries and responsible risk factors. Int J Antimicrob Agents, 2004; 24(2):105-110.

Centers for Disease Control and Prevention. 2014. Mission Critical: Preventing Antibiotic Resistance. [ONLINE]Available at:https://www.cdc.gov/features/antibioticresistance/index.html.[Accessed 04 September 2017].

Chu E, Hamp A. "Generic Vs. Brand drugs: Which is Better? The cost savings of generic latanoprost may improve compliance, for example, but does the generic "equivalent" work as well as the brandname drug?" Review of Optometry. 2012.[ONLINE]. Available at: https://www.reviewofoptometry.com/article/generic-vs-brand-drugswhich-is-better. [Accessed 30 August 2017].

Colgan S, Faasse K, Martin LR, Stephens MH, Grey A, Petrie KJ. Perceptions of generic medication in the general population, doctors and pharmacists: a systematic review. BMJ Open, 2015;5:e008915

Davey P, Pagliari C, Hayes A. The patient's role in the spread and control of bacterial resistance to antibiotics. Clin Microbiol Infect 2002; 8(s2):43-68.

Dua V, Kunin CM, White LV. The use of antimicrobial drugs in Nagpur, India. A window on medical care in a developing country. Soc Sci Med, 1994; 38(5):717-724.

Escourrou B, Bouville B, Bismuth M, Durrieu G, Oustric S. Self-medication in children by parents: a real risk? A cross-sectional descriptive study. La Revue du praticien, 2010; 60(6 Suppl):27-34.

Fluit AC, Visser MR, Schmitz F-J. Molecular detection of antimicrobial resistance. Clin Microbiol Rev, 2001; 14(4):836-871.

García C, Llamocca LP, García K, Jiménez A, Samalvides F, Gotuzzo E, Knowledge, attitudes and practice survey about antimicrobial resistance and prescribing among physicians in a hospital setting in Lima, Peru. BMC Pharmacol Toxicol, 2011; 11(1):18.

Giblin TB, Sinkowitz-Cochran RL, Harris PL, Jacobs S, Liberatore K, Palfreyman MA, et al. Clinicians' perceptions of the problem of antimicrobial resistance in health care facilities. Arch Intern Med, 2004; 164(15):1662-8
Guerra CM, Pereira CAP, Neto ARN, Cardo DM, Correa L. Physicians' perceptions, beliefs, attitudes, and knowledge concerning antimicrobial resistance in a Brazilian teaching hospital. Infect Control Hosp Epidemiol, 2007; 28(12):1411-1414.

Hameed A, Naveed S, Qamar F, Alam T, Abbas SS, Sharif N. Irrational use of antibiotics, in different age groups of Karachi: A wakeup call for antibiotic resistance and future infections. J Bioequiv Availab, 2016; 8:242-245.

Hanif A, Ashar SM, Rabnawaz R, Yasmeen S. Self-medication of antibiotics among the students of Hamdard University, Pakistan. J Public Health Dev Ctries, 2016; 2(1):145-148.

Haseeb A, Bilal M. Prevalence of using non prescribed medications in economically deprived rural population of Pakistan. Arch Public Health, 2016; 74:1.

Ijoma U, Onwuekwe I, Onodugo O, Aguwa E, Ejim E, Onyedum C, Onah L, Okwudire E, Ugwuonah G. Effect of Promotional Strategies of Pharmaceutical Companies on Doctors' Prescription Pattern in South East Nigeria. TAF Prev Med Bull, 2010; 9(1):1-6.

Istúriz RE, Carbon $\mathrm{C}$. Antibiotic use in developing countries. Infect Control Hosp Epidemiol, 2000; 21(6):394-397.

Kamat VR, Nichter M. 1997. Monitoring product movement: an ethnographic study of pharmaceutical sales representatives in Bombay, India. In: Bennett S, McPake B, Mills A, eds. Private health providers in developing countries: serving the public interest? London: Zed Press.

Khan S, Shehzad A, Shehzad O, Al-Suhaimi EA. Inpatient antibiotics pharmacology and physiological use in Hayatabad medical complex, Pakistan. Int J Physiol Pathophysiol Pharmacol, 2013; 5(2):120.

Livorsi D, Comer AR, Matthias MS,Perencevich EN, Bair MJ. Factors influencing antibiotic-prescribing decisions among inpatient physicians: a qualitative investigation. Infect Control Hosp Epidemiol, 2015; 36(9): 1065-1072.

Madani TA, Al-Abdullah NA, Al-Sanousi AA, Ghabrah TM, Afandi SZ, Bajunid HA. Methicillin-resistant Staphylococcus aureus in two tertiary-care centers in Jeddah, Saudi Arabia. Infect Control Hosp Epidemiol, 2001; 22(4):211-216.

McNulty CA, Boyle P, Nichols T, Clappison P, Davey P. Don't wear me out - the public's knowledge of and attitudes to antibiotic use. J Antimicrob Chemother, 2007; 59(4):727-738.

Metlay JP, Shea JA, Crossette LB, Asch DA. Tensions in antibiotic prescribing. J Gen Intern Med, 2002; 17(2):87-94.

Mohan S, Dharamraj K, Dindial R, Mathur D, Parmasad V, Ramdhanie $\mathrm{J}$, et al. Physician behavior for antimicrobial prescribing for paediatric upper respiratory tract infections: a survey in general practice in Trinidad, West Indies. Ann Clin Microbiol Antimicrob, 2004; 3(1):11.

Naveed S, Qamar F, Maqsood A, Ayub A, Kauser H, Malik H, Fatima K, Hameed A. prevalence and consequences of misuse of antibiotics, survey based study in Karachi. J Bioequiv Availab, 2015;7:202-204.

Nizami S, Khan I, Bhutta Z. Drug prescribing practices of general practitioners and paediatricians for childhood diarrhoea in Karachi, Pakistan. Soc Sci Med, 1996; 42(8):1133-1139.

Pakistan Medical and Dental Council. Statistics. 2015 [ONLINE]Available

at:http://www.pmdc.org.pk/Statistics/tabid/103/Default.aspx. [Accessed 29 July 2015].

Pedersen K, Pedersen K, Jensen H, Finster K, Jensen VF, Heuer OE. Occurrence of antimicrobial resistance in bacteria from diagnostic samples from dogs. J Antimicrob Chemother, 2007; 60(4):775-81.

Prats G, Mirelis B, Llovet T, Muñoz C, Miró E, Navarro F. Antibiotic resistance trends in enteropathogenic bacteria isolated in 19851987 and 1995-1998 in Barcelona. Antimicrob Agents Chemother, 2000; 44(5):1140-1145

Rafeeque M. Irrational use of antibiotics in India: Time to work together. J Pharm Prac Community Med, 2016;2(1):29.

Sebsibie G, Gultie T. Retrospective Assessment of Irrational use of Antibiotics to Children Attending in Mekelle General Hospital. Sci J Clin Med, 2014; 3(3):46-51.

Shahid A, Iftikhar F, Arshad MK, Javed Z, Sufyan M, Ghuman RS, Tarar Z. Knowledge and attitude of physicians about antimicrobial 
resistance and their prescribing practices in Services hospital, Lahore, Pakistan. J Pak Med Assoc, 2017; 67(6):968-972.

Shehadeh M, Suaifan G, Darwish RM, Wazaify M, Zaru L, Alja'fari S. Knowledge, attitudes and behaviour regarding antibiotic use and misuse among adults in the community of Jordan. A pilot study. Saudi Pharm J, 2012; 20(2):125-133.

Smith RD, Coast J. Antimicrobial resistance: a global response. Bull World Health Organ, 2002;80(2):126-133.

Srinivasan A, Song X, Richards A, Sinkowitz-Cochran R, Cardo D, Rand C. A survey of knowledge, attitudes, and beliefs of house staff physicians from various specialities concerning antimicrobial use and resistance. Arch Intern Med, 2004; 164(13):1451-1456.

Stille CJ, Rifas-Shiman SL, Kleinman K, Kotch JB, Finkelstein JA. Physician responses to a community-level trial promoting judicious antibiotic use. Ann Fam Med, 2008; 6(3):206-212.

Thriemer K, Katuala Y, Batoko B, Alworonga J-P, Devlieger H, Van Geet C, Antibiotic prescribing in DR Congo: a knowledge, attitude and practice survey among medical doctors and students. PLoS One, 2013; 8(2):e55495.

van Staa A. 1993. Myth and metronidazole in Manila: the popularity of drugs among prescribers and dispensers in the treatment of diarrhoea. Masters thesis, Anthropology, University of Amsterdam.

Weir RE, Zaidi FH, Charteris DG, Bunce C, Soltani M, Lovering AM. Variability in the content of Indian generic ciprofloxacin eye drops. Br J Ophthalmol, 2005 Sep;89(9):1094-1096.

Wester CW, Durairaj L, Evans AT, Schwartz DN, Husain S, Martinez E. Antibiotic resistance: a survey of physician perceptions. Arch Intern Med, 2002; 162(19):2210-2216.

Wolffers I. Drug information and sale practices in some pharmacies of Colombo, Sri Lanka. Soc Sci Med, 1987; 25(3):319-21.

Workneh BD, Gebrehiwot MG, Bayo TA, Gidey MT; Belay YB, Tesfaye DM, Kassa TT. Influence of Medical Representatives on Prescribing Practices in Mekelle, Northern Ethiopia. PLoS ONE, 2016;11(6):e0156795.

World Health Organization. 2004. The World Medicines Situation; World Health Organization: Geneva, Switzerland.

World Health Organization. 2012. The evolving threat of antimicrobial resistance: options for action: Geneva, Switzerland.

\section{How to cite this article:}

Faizullah M, Rahman N, Umar MI, Anwar M, Sarfraz M. A crosssectional study on knowledge, attitude and practices of medical doctors towards antibiotic prescribing patterns and resistance in Khyber Pakhtun Khawah, Pakistan. J App Pharm Sci, 2017; 7 (12): 038-046. 